\title{
Service-oriented Cost Allocation for Business Intelligence and Analytics: Who pays for BI\&A?
}

\author{
Raphael Grytz \\ University of Paderborn \\ grytz@aisbi.de
}

\begin{abstract}
Quantifying and designing the cost pool generated by Business Intelligence and Analytics (BI\&A) would improve cost transparency and invoicing processes, allowing a fairer, more exact allocation of costs to service consumers. Yet there is still no method for determining $B I \& A$ costs to provide a base for allocation purposes. While literature describes several methods for BI\&A cost estimation on an ROI or resource-consumption level, none of these methods considers an overall approach for BI\&A. To tackle this problem, we propose a service-oriented cost allocation model which calculates BI\&A applications based on defined services, enabling a cost transfer to service consumers. This new approach specifies steps towards deriving a usable pricing scheme for an entire BI\&A service portfolio - both for allocation purposes as well as improving cost evaluation of BI\&A projects. Moreover, it prevents $B I \& A$ departments from being considered as the sole cost driver, increasing customer understanding and cost awareness.
\end{abstract}

\section{Introduction}

In the information age, it is becoming increasingly important for companies to recognize and harness the potential of internal and external data. To successfully compete on the market, information for decision-making processes must be provided at the right time and in a suitable form. In general, this is the task of Business Intelligence and Analytics (BI\&A). Chen et al. [6] define BI\&A as "the techniques, technologies, systems, practices, methodologies, and applications that analyze critical Business data to help an enterprise better understand its business and market and make timely decisions". The principal purpose of BI\&A is to use past experience to support decision making. The majority of organizations have an internal department for BI\&A, in most cases structured as a BI Competency Center (BICC) [20], which provides this information through a company-specific BI\&A architecture and

\author{
Artus Krohn-Grimberghe \\ University of Paderborn \\ artus@aisbi.de
}

organization. Today the benefits of BI\&A are undisputed and it has reached most organizations. Due to rising costs as well as a more complex architecture [13], in addition to new technology and methods [6], BI\&A requires justification to management, especially during difficult economic times [10, 18], and this is supported by a more differentiated cost transparency.

While there are some frameworks for summing up the total cost for BI\&A technology landscapes $[27,18]$ and some approaches which propose an estimation of costs based on resource consumption [4, 16] (cp. Section 2.2 and 4.1), a detailed, holistic $\mathrm{BI} \& \mathrm{~A}$ cost allocation approach is missing. More specifically, there is no description of the steps required of the BI\&A function in a company in order to create a practicable pricing scheme with a view to allocating costs to BI\&A customers, nor are there blueprints for the structure of such a scheme.

According to a recent study by the market research organization Dynamic Markets, 72 per cent of the companies surveyed are not able to identify their BI\&A reporting costs [8]. Moreover, allocating those costs to the level of individual BI\&A applications [21,9] remains a challenging task. This difficulty arises because BI\&A applications are complex due to both their development process and interdependencies; another issue is the individual nature of a company's BI\&A product portfolio, with customer requirements in continuous flux. However, in order to allocate costs in a fair way, the total BI\&A cost must be broken down so as to make the individual $\mathrm{BI} \& \mathrm{~A}$ activities visible and to determine costs at the BI\&A activity level (e.g., user support, operating costs for a report). In a BI\&A context, this becomes complex because of predominantly fixed and indirect costs [16, 9], which makes cost allocation necessary. Viewed from an IT perspective, $[2,26]$ point out that IT costs must be allocated in order to improve cost transparency and that this is a challenging task beset by problems which remain unresolved [2] (e.g. overhead allocation problems, accounting conventions).

It is the aim of this paper to increase BI\&A cost transparency by applying an appropriate cost 
accounting system driven by a BI\&A controlling instrument. This kind of BI\&A cost accounting system will be available as a managerial instrument for collecting information about value streams in order to plan, control and monitor all tasks in the BI\&A organization [12]. With an appropriate cost accounting system, cost transparency will increase, helping managers take decisions [21]. It will also become possible to calculate costs for both individual $\mathrm{BI} \& \mathrm{~A}$ artefacts and entire BI\&A projects. Moreover, if they are charged with BI\&A costs, customers within a company may also become sensitized to the importance of making economical use of BI\&A. Furthermore, an improvement in cost controlling could bring about a more efficient and effective use of BI\&A resource project planning. Aside from the possibility of enabling make-or-buy decisions and cost benchmarks, improved cost transparency will represent a step forward towards a profitability analysis.

In order to create a cost accounting system for BI\&A, single BI\&A activities or services (discussed later in this paper) have to become calculable. To achieve this aim, we present a four-step process model for BI\&A service-oriented cost allocation. The initial step is to create service integration. We therefore use the existing activity portfolio representing the entire competence of a BI\&A organization, grouping together all BI\&A activities in order to break them down into single BI\&A services. Secondly, a cost allocation structure is created which defines the distribution of BI\&A costs to the BI\&A services by considering the application portfolio, the user directory and BI\&A-relevant cost centers. Thirdly, single cost elements such as personnel, infrastructure or consulting costs are collected and applied to this accounting net in order to form the cost model. Following this step, all BI\&A services in the organization have a price tag. Finally, all BI\&A services are communicated to consumers through a BI\&A service catalogue.

The rest of this paper is organized as follows. Section 2 discusses the related work. First, we look into cost accounting approaches for BI\&A: the coarsely outlined methods we describe in section 2.1 represent the only work to date. This lack of detailed approaches leads us to refer to related fields in section 2.2, which we find mostly in IT cost accounting literature. In chapter 2.3 , we analyze this literature critically and summarize useful work for a first concept. Although BI\&A is driven by IT [1, 22, 6], due to fundamental differences such as architecture and business domain, the IT-related work is not directly applicable to BI\&A: we highlight this in section 2.4. In section 3.1 and section 3.2, we describe how we build up a BI\&A cost allocation structure from the bottom up. In Section 4, we propose a model for an internal BI\&A cost allocation system which implements accounting as an overall approach. Section 5 summarizes our contributions, analyses them critically and provides an outlook onto further research needs. Our main contributions are:

- an overview of cost accounting approaches from a BI\&A and IT perspective,

- a differentiation between BI\&A and IT,

- a definition of requirements for BI\&A cost accounting in comparison to IT

- a definition of a BI\&A output hierarchy,

- an introduction to a BI\&A-specific cost accounting approach with an example of use.

\section{A brief overview of the current research on BI\&A cost accounting}

The existing literature provides no concrete approaches for solving the BI\&A cost accounting issue in an overall context from the perspective of a company. However, in this section, some useful work on subareas of BI\&A and IT concepts which could form the base for a new BI\&A specific cost accounting approach is briefly described. As the number of publications addressing BI\&A cost accounting is limited, we extended our survey to include the IT perspective in an effort to present a variety of approaches and assess their applicability for BI\&A purposes. We chose methods, concepts, and ideas from the academic literature as well from publications by BI\&A/IT professionals or companies which deal with this topic and offer pertinent approaches to improving BI\&A cost accounting. First, we introduce BI\&A-relevant contributions, followed by IT-relevant contributions dealing with cost accounting of IT artefacts.

\subsection{Cost accounting - BI\&A perspective}

Klesse [16] focuses on a method of carrying out cost allocation for data warehouse competency centers (DWH CC). The products and services of the DWH CC are modeled as "information products" for which platform and process services must be assigned in detail. Due to the fact that the resulting cost accounting system is based on this information product model, accounting can be carried out in a very detailed manner on the costs-by-cause principle.

Gansor et al. [9] describe the development and operation of a BI competency center (BICC) by considering a wide range of topics: e.g. BI strategy or BI controlling. It is important for the customer to 
show which services are provided, whether once or on a regular basis, at what level of quality, and at what cost. Due to the multi-level process for generating information and intra-divisional use, it is difficult to determine the cost of a specific piece of information. The authors briefly outline three approaches to realize an internal cost allocation: flatrate distribution keys, usage-dependent allocation and a BI-project oriented approach.

\subsection{Cost accounting - IT perspective}

Hamel et al. [12] present an overview of relevant scientific work regarding the topic of IT cost accounting between 2000 and 2010. Although the focus of this work is on IT controlling, the paper is an anchor for our review, as it covers established IT controlling literature and provides a synthesis of relevant articles from information systems journals.

Cannon et al. [5] describe a collection of best practices for IT service management, and is known as the IT infrastructure library (ITIL). The financial management component for IT services is described as the process which manages the budgeting, accounting, and charging requirements of IT services. One element is a set of cost models identifying expenditures and describing how costs relate to services and/or customers. These cost models are then used as a financial baseline from which to derive costs or pricing.

Bertleff [3] mentions that the objectives of a cost allocation approach should be derived from corporate strategy and must be clarified before implementation. Bertleff points out that allocation by technical factors such as CPU usage or storage I/O cannot be applied due to the difficulty of understanding and planning the resource consumption for customers. Therefore, a cost model is presented which distinguishes between an external view for the customer (product-oriented), and an internal view representing single IT activities. Forming an IT product is described as complex and is not further specified.

The paper by Brandl et al. [4] introduces a method aimed at determining usage-based cost allocation keys for customer-oriented services based on their estimated resource consumption. This can be achieved if every user request is tracked by a unique user ID, resulting in a detailed monitoring and metering of users' resource consumptions.

\subsection{Concept creation}

The approaches screened in this paper are intended to provide an overview of appropriate approaches to allocating BI\&A costs. We can conclude that the literature discusses four types of cost accounting for BI\&A: 1. No allocation of costs is executed; 2. Costs are allocated using flat-rate distribution keys; 3. Costs are charged by a production-oriented allocation base, e.g. CPU or memory utilization; 4. Costs are calculated by product-oriented approaches, which are too technical and very detailed in their present form. It is worth noting that none of the approaches introduced here refers to BI\&A accounting in a holistic, companylevel way. The methods presented here are on a very high level of abstraction, making it difficult to evaluate their practicability.

There are, however, general and detailed accounting ideas which may be adaptable to individual components of BI\&A architecture. The approaches presented by Klesse [16] or Brandl et al. [4] attempt to solve aspects of this problematic situation, but because of their meticulous methods, we assume they would incur very high expenses in practice. While it could indeed lead to a fair allocation of costs, the direct implementation of both methods as BI\&A cost allocation approaches would result in an uneconomical BI\&A cost accounting system. Standard publications regarding IT controlling, such as ITIL by Cannon et al. [5] or Hamel et al. [12], provide an overview of IT controlling, but the description of individual concepts remains very general. In this paper, we concentrate on a usage-dependent allocation of BI\&A costs such the approach proposed by [9]; the method has to be practicable and support a fair allocation of costs. In addition, we consider the fundamental elements of an accounting system by Klesse [16] as a starting point for a new accounting model. This model is also supported by Bertleff's [3] idea of generating services for a service consumer. In summary, many questions remain with regard to BI\&A cost accounting. We need to know how to derive a BI\&A service portfolio and the underlying cost model to generate prices for single services.

\subsection{BI\&A in comparison to IT}

BI\&A is understood as a sub-area of IT [6] and, as such, the overall cost structure within a company of both BI\&A and IT is similar. Fundamentally, both areas have fixed costs for hardware, software and personnel [22, 16]. However, there are also substantial differences between IT and BI\&A.

One difference lies in the fact that all BI\&A applications have a higher degree of interdependencies than is common for IT applications, as BI\&A applications are typically 
based on a monolithic architecture. The main difference here is that this BI\&A architecture is not static. Each architectural element experiences changes, updates and upgrades over time, and will be used in and affected by a variety of projects [23]. The monolithic BI\&A architecture leads to a huge pool of indirect costs for the BI\&A software and hardware used, whereas IT services such as specific standalone software applications often operate detached from one another and create direct costs which are easier to allocate to a service consumer. How could the costs for a single report (reports being different from a development point of view inasmuch as a report's complexity and consumption of resources could increase by a single measure [1]) or an analytic application be determined in a sensible way? This question could be answered by using a special BI\&A cost accounting approach as detailed in this paper.

Another area in which BI\&A and IT differ is the business domain. While BI\&A mainly provides information across organizational units within a company [21] - and supports executives and management - IT concentrates on the company-wide availability of information technology to support value-added processes in the classic sense [9]. This means that BI\&A must deal with various delivery systems and transform raw data into valuable data for supporting the decision-making process while keeping in mind the organization-wide requirements of a much larger set of stakeholders than operational systems projects [23].

This also leads to a differentiation between IT and BI\&A requirements. BI\&A is affected by complicated interdependencies regarding technical requirements across many business functions as well as levels of management interests that lead to a higher level of complexity. In most cases, heterogeneous departmental objectives must be merged due to a lack of standardized managerial activities; this situation is different when it comes to transaction or operational systems hosted by IT departments [21].

Another point of differentiation can be found in the development process. IT, for instance, is characterized by the provision of hardware (PC workplace) and standard or individual software to support the execution of operational activities within a company. BI\&A differs from IT in its integrated nature. Consequently, a plethora of tools is generally used in the process of creating BI\&A applications. Cost accounting, therefore, becomes more complex, as corresponding resources are shared. In addition, due to dependencies and close links between parts of the operational systems [21], a higher complexity is to be expected in the BI\&A development process.
In sum, due to both their developmental and operational architecture, their business domain, and their technical and functional requirements, BI\&A applications differ from classic IT applications and must therefore be treated differently.

\section{BI\&A cost accounting: problems and challenges}

In this section we describe the problems which occur if BI\&A cost accounting is not applied. Furthermore we describe requirements for a cost accounting system that are differentiated from the IT perspective and therefore have to be considered by a BI\&A cost accounting approach.

\subsection{Lack of cost transparency}

In Section 1, we discussed the lack of cost transparency as one of the principal issues when cost accounting for BI\&A is neglected. Due to the lack of cost transparency, four further problems arise.

Firstly, there is no possibility of charging BI\&A costs to service consumers in a fair way. In order to do so, costs must be broken down so that individual BI\&A activities are visible. In a cost accounting context, fair allocation means that service consumers have to pay the cost they cause.

Secondly, BI\&A efforts cannot be considered reliably in project calculations (internal and external view). The assessment of either a company's entire $\mathrm{BI} \& \mathrm{~A}$ investments or of individual BI\&A applications' cost-effectiveness cannot be concluded. In general, when BI\&A is organized as a BICC, it is perceived as an economically active organization and, therefore, BI\&A projects are approached without any reliable figures. Consequently, companies presume value for costs and thus do not carry out any accounting of BI\&A costs [24].

Thirdly, outsourcing decisions with respect to parts of the BI\&A portfolio cannot reasonably be pursued. Enormous cost pressure is leading companies to look for new outsourcing possibilities; meanwhile, the relevance of delivering BI\&A as a service is constantly becoming more important [1, 11]. However, in order to evaluate outsourcing decisions on individual BI\&A applications, their internal costs must be known (or at least a reasonable estimate of them) [15].

Fourthly, from an organizational point of view, it is difficult to identify potential to improve efficiency and productivity, to plan the use of resources and justify this use to management. With improved cost transparency, a BI\&A department is able to locate 
cost savings and cost drivers. In addition, with the ability to calculate BI\&A applications, incoming BI\&A demands could be prioritized under consideration of their expected benefit (value). This will improve the efficiency (cost-benefit perspective) of the whole BI\&A department as well as the use of $\mathrm{BI} \& \mathrm{~A}$ resources for higher productivity

\subsection{Requirements for BI\&A cost accounting}

The differences between BI\&A and IT mentioned in Section 2.4. lead to a different way of allocating or charging costs. Consequently, cost accounting approaches - even if applicable for IT cost allocation - need careful examination and adaptation before they can be applied to BI\&A cost allocation. Therefore, the essential requirements for a cost accounting system and internal cost allocation have to be examined too [14]. A comparison has to be made between the BI\&A and IT perspectives since, on the one hand, these requirements differ in their understanding and realization and, on the other hand, the differentiation between the two may enable a new approach to be developed with regard to BI\&A cost accounting. The following paragraphs describe the essential requirements for a cost accounting system by comparing BI\&A and IT.

Fair allocation of BI\&A/IT applications or activities: As compared to IT, BI\&A has a shared infrastructure made up predominantly of fixed costs. Therefore, a fair allocation of BI\&A is realized by taking into consideration the complexity of a BI\&A application created over the layered and (often) monolithic BI\&A architecture (exact monitoring is expensive, a more economical approach is required).

Transparent and comprehensible pricing: For acceptance reasons, a service consumer should be able to understand how the price of a BI\&A application or an activity has been derived. Due to the complexity of BI\&A, providing an explanation for a price is a completely different activity than in IT. The price of a PC workplace or hosted software, for example, is calculated using the corresponding hardware or licensing costs. To calculate a price for a report, relevant costs within the BI\&A architecture must be estimated. In this case, multiple components are shared by other BI\&A applications.

Understandable definitions of BI\&A/IT activities for service consumers: A service consumer should be able to understand which activities are included when, buying a BI\&A application. Activities clearly differ depending on the areas described (e.g., DWH development in BI\&A and installation of a PC workplace in IT).
Equal treatment of all service consumers: This requirement is especially difficult to realize in BI\&A. For example, two apparently identical reports could be assigned the same fee. It would only take one measure to be altered, however, to change the complexity of a report, thereby significantly increasing the use of resources. For equal treatment, a new fee would subsequently be required.

Economically justifiable execution of cost allocation: To satisfy this requirement in terms of the complex topic of BI\&A, an approach needs to be realizable without disproportionate effort.

Compatibility with the cost accounting system: Since BI\&A/IT accounting costs fall under the controlling and cost accounting area, any approach must be compatible with this field. Furthermore, considering the constant change in the BI\&A environment, a potential approach should have a degree of flexibility and not be based on any specific technology.

\section{Paying for BI\&A}

This paper contributes to creating and improving cost transparency for in-house BI\&A departments. We propose structuring a company's BI\&A cost pool in a way such that single (planned or existing) applications become calculable on the basis of cost. More precise accounting allows for better internal invoicing to the service consumers of the BI\&A artefacts. In turn, this cost allocation system prevents the BI\&A department from being considered as the sole cost driver (cost sink). Through defining BI\&A services, customer understanding increases and service consumers are made aware of the importance of using BI\&A in an economic way.

\subsection{Applying IT cost allocation approaches}

We will begin by examining the approaches found from the IT perspective. Cannon et al. [5] present a variety of commonly-used cost models for supporting IT service management. Viewing the ideas mentioned from a cost perspective, Cannon et al. use a bottom up-approach which means that costs identified are separated into direct and indirect costs and then assigned to a department or customer. An allocation is only briefly discussed; one elementary step missing is the top-down definition and creation of services. For better resource planning and comprehensibility, customers need an overview of the services available. The cost models introduced are useful, but a clear way of constructing a holistic cost model is absent. 
Bertleff [3] introduces an allocation model based on defined IT products, e.g. a standard office working place. This IT product consists of hardware or software costs as well as of costs for infrastructure and internet. The idea is to create a bridge for customers from technical IT resources to understandable IT products. From a BI\&A perspective, this approach is not complete because the IT resource in question consists mostly of direct costs. It is therefore not difficult to map standard office workspace to the IT product. Yet a large pool of indirect BI\&A costs remains unallocated. Furthermore, no way of deriving IT "products" which could translate to BI\&A services is described.

Brandl et al. [4] introduce resource profiles used for the allocation of shared IT infrastructures. This approach detects the IT resource consumption of every user request. An allocation of costs for a BI\&A system landscape would result in a detailed approach which, from our point of view, would incur substantial outlay. There is neither any indication of how to bring this method to a holistic IT allocation approach, nor of how to adapt this idea to BI\&A.

We conclude that there is no direct applicability of the IT cost accounting approaches discussed to BI\&A. This is understandable given the fact that the approaches have no reference to BI\&A. Another reason is the lack of detail, as only a brief overview of cost accounting ideas is presented or there is a focus limited to one sole specific element.

\subsection{BI\&A Service-Oriented Cost Allocation}

To achieve cost transparency by introducing a BI\&A cost allocation system, we propose the following BI\&A output hierarchy (see Figure 1).

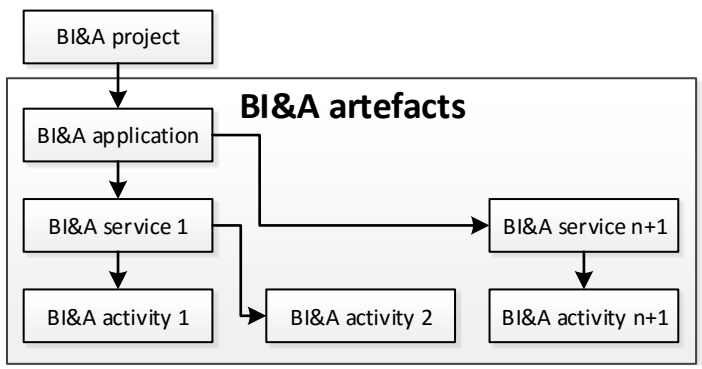

Figure 1. BI\&A output hierarchy

As previously mentioned, a result of this paper is the specification of BI\&A services, which are product-oriented artefacts from the service consumer point of view. A BI\&A artefact is a general description of any output of a BI\&A organization such as a developed report or daily DWH monitoring.
A BI\&A service consists of single BI\&A activities. These activities are internal actions: development as a service, for instance, consists of activities such as project management or requirements definition. With several BI\&A services, a single BI\&A application could be specified and calculated. By way of example, an application would typically consist of initial services for development and of recurring services for operations. Beyond that, it would be possible to value a BI\&A project consisting of one or more BI\&A applications.

In order to quantify single BI\&A applications, we propose an internal cost allocation under consideration of BI\&A-specific characteristics as well as the requirements from Section 3.2. Working on the assumption of a shared service center, which is a common form of organization for BI\&A, and of a high degree of customer orientation, in the following we use the term Business Intelligence \& Analytics Service-Oriented Cost Allocation (BIASOCA). This BIASOCA consists of: service integration, accounting net, cost model and service catalog which latter describes the defined BI\&A services. Our proposed process model is illustrated in Figure 2.

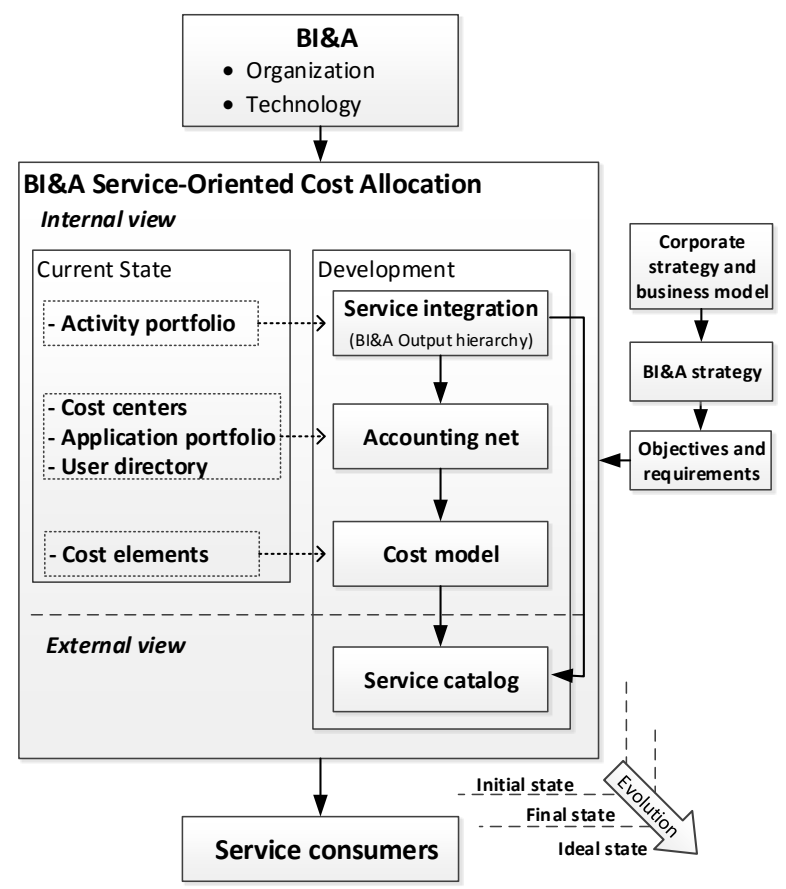

Figure 2. Process model of the BIASOCA

This approach achieves a simplified usagedependent allocation based on Gansor et al. [9] and works on the basis of the general model by Klesse [16]. Gansor et al. [9] describe using distribution keys e.g. measurement by memory consumption, development hours or the quantity of reports. 
Klesse [16] speaks of internal components such as the cost accounting system and external components, which are products or services, a cost model and a pricing model. Yet he only considers the DWH perspective.

Single BI\&A activities are packaged through several steps to form services; these are in turn the major elements of allocation and communication to the internal or external service consumer. The accounting net defines the method of determining price. The objective is to simultaneously achieve both a sufficiently fair allocation of the costs incurred and a level of practical feasibility. In the cost model, transparency is provided by a total cost investigation, while the calculation method defined determines transfer prices for single services. In addition, it is possible to intervene by using political prices.

The BI\&A service catalog is understood as a platform for using and communicating services. This catalog offers a description, transfer prices and presents the activities included. By setting targets and requirements for the process model based on the BI\&A strategy, a strategic alignment towards the business model as well as the corporate strategy is considered. The next few sections describe the elements of the model presented in detail.

\subsection{Service integration}

In companies, the BI\&A department has to provide the resources required in the form of a BI\&A organization and $\mathrm{BI} \& \mathrm{~A}$ technology to generate $\mathrm{BI} \& \mathrm{~A}$ activities. As a general rule, although identical in appearance, no two products - e.g. two reports - will be comparable per se. Therefore, it is necessary to structure all activities in categories to allow a differentiated evaluation of products such as reports. Derived services in this part of the process model can then be given a fixed price or, depending on the individual outlay consumed by a specific application, be calculated dynamically, making the figures more exact and fairer. Operating costs, for instance, are allocated using a fixed charge, whereas development activities are considered by variable costs in the form of hours worked.

The basic idea of service integration is to determine which activities are perceived as an integrated product forming a discreet BI\&A service. Hence these activities have to be grouped so as to offer and later allocate these defined services to service consumers. Attention must be paid to describing both single activities and aggregated services in an understandable way. The activity portfolio has to be documented as a relevant input variable for service integration. It summarizes all of the in-company activities which are created by a BI\&A department.

On the one hand, these activities are shared collaboratively by multiple departments, e.g. monitoring ETL processes or operating cubes. On the other hand, there are activities that could be assigned directly to a service consumer, such as supporting and supervising projects, development or training.

Service integration is now pursuing the aim of grouping activities to define a structure for deriving BI\&A services. These services represent cost objects in our model. By using structured methods, e.g. card sorting [25], it is possible to define loose categories which can then be refined in the further course of company-specific analysis. As a basic structure, we propose categorizing by operation, development, consulting and training.

Figure 3 shows an example for service integration. In operations, all BI\&A applications as well as all BI\&A users and service consumers are supported. At this point, a second stage of service integration takes place. All activities with a direct connection to operating applications and offering

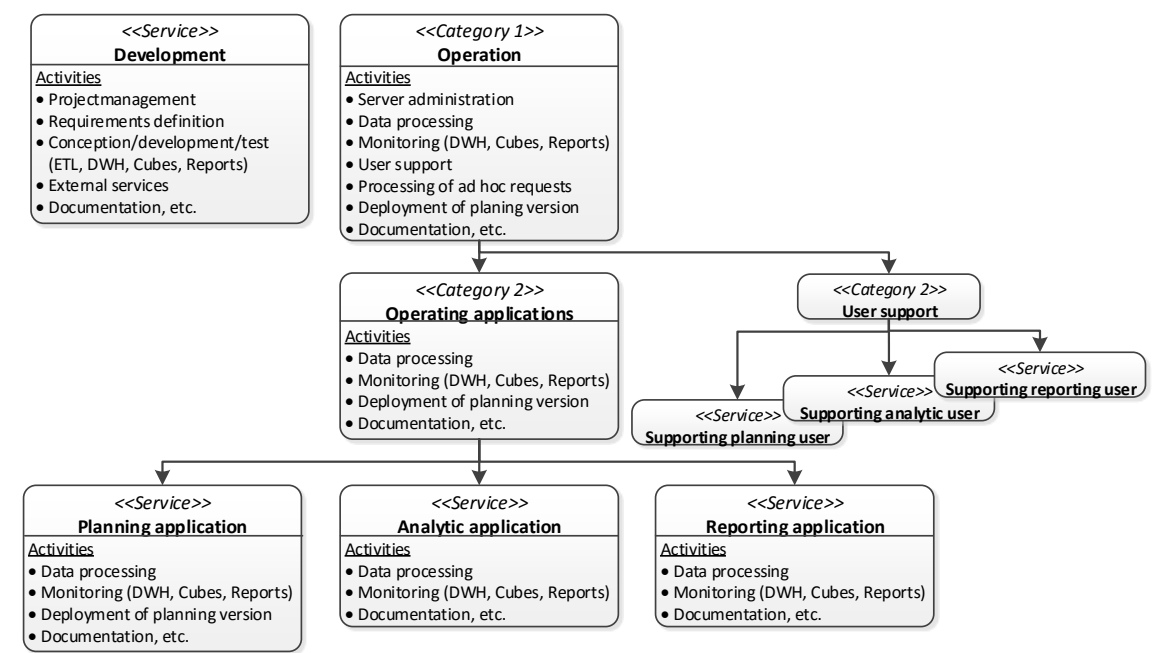

Figure 3. Service integration 
user support are summarized again. In our example, we assume that costs for operating reporting, analytics and planning applications have to be considered. Therefore, single BI\&A services for these three different types of application are created.

Aside from the applications, this necessitates service charges for different user roles, as specified in the 'user support' category (not described in detail). For instance, access to the reporting system is considered by the 'supporting reporting user' service, while analysis activities are taken into account by the 'supporting analytic user' service. In addition to the operating activities, a service for BI\&A development is described. For better understanding, services for consulting and training are not included in this paper.

In order to meet the requirement of an economically justifiable execution (Section 3.2.) for the BIASOCA, it is not possible to respond to every information need and charge it to the corresponding service consumer. Therefore, items requiring more than eight hours of development or consulting outlay, for example, are charged separately.

Consequently, the development of a simple report is covered by charging the 'reporting application' operation to a service consumer, whereas a complex report is calculated additionally using the BI\&A development service. Because services for consulting and training can be assigned directly to a service consumer, they too are specified separately.

\subsection{Accounting net and cost model}

The accounting net adds allocation methods to service integration, representing the connection between the BI\&A department and service consumers. It shows the BIASOCA as a cost accounting system. Determining primary and secondary cost centers creates a base on which to build the accounting net. In this step, BI\&A costs that are not assigned to the BI\&A cost centers should be detected and corrected. The cost view is then expanded into a more detailed cost documentation created by using the total cost of ownership (TCO). The objective here is to localize all direct and indirect costs that are created by the BI\&A department in order to create cost transparency.

The accounting net documents how transfer prices are determined for defined BI\&A services. In addition, allocation bases as well as required distribution keys are provided. Because most of the monthly costs incurred in a BI\&A department are fixed costs, this gives rise to the question of how these costs should be assigned to the services. To meet the requirement of an economically justifiable BIASOCA, we suggest using distribution by time recording. This implies an obligatory time recording for the BI\&A organization: any logging of working time has to be discussed with employees affected as well as - in Germany - with the worker's council. It is, however, eminently possible to document the time required per activity and thus to measure the total effort, e.g. for the 'operations' or 'user support' categories. Continuous time recording allows for a more realistic distribution key by average values over a year and for adjusting for seasonal/ calendar effects.

As BI\&A applications are complex and have different resource consumptions in operations, deriving a distribution key is no simple task. One method would be to attempt to measure the exact load caused by any single component of a BI\&A system. However, in most environments, this is either downright impossible, or at the least very costly and cumbersome. Instead, we recommend approximating the operation costs using a method based on a more abstract level. Here, it is necessary to value the complexity for every BI\&A application in the application portfolio, for instance by using the threetier architecture (data warehouse, cube layer, front end). By summarizing the single evaluations per application, a distribution key is developed for the different application types (see Table 1).

Table 1. Calculation of distribution key

\begin{tabular}{|c|c|c|c|c|}
\hline $\begin{array}{c}\text { Application } \\
\text { Type }\end{array}$ & Application name & $\begin{array}{l}\text { Three-Tier- } \\
\text { Complexity }\end{array}$ & $\begin{array}{c}\text { Complexity } \\
\text { Costs }\end{array}$ & $\begin{array}{c}\text { Distribution } \\
\text { key }\end{array}$ \\
\hline Reporting & Daily Values & 4 & $3.555,56 €$ & $39 \%$ \\
\hline application & Dashboard & 3. & $2.666,67 €$ & \\
\hline $\begin{array}{l}\text { Analytic } \\
\text { application }\end{array}$ & CRM Analysis & 5 & $4.444,44 €$ & $28 \%$ \\
\hline $\begin{array}{l}\text { Planning } \\
\text { application }\end{array}$ & Sales Planing & 6 & $5.333,33 €$ & $33 \%$ \\
\hline & Operation Costs & 18 & $16.000,00 €$ & $100 \%$ \\
\hline & $\begin{array}{c}\text { Costs per } \\
\text { Complexity }\end{array}$ & 1 & $888,89 €$ & \\
\hline
\end{tabular}

The cost model enhances the accounting net by adding the cost view. Thus, cost drivers will be identified while complete cost transparency is created. In order to determine the transfer prices of the BI\&A services, the accounting net and the cost documentation, e.g. cost centers, are combined. The total monthly BI\&A costs are thus distributed as planned costs [7] to BI\&A services. Before single transfer prices are generated, the whole output to all service consumers has to be determined per BI\&A service. The output in 'operating applications' is determined as the sum of all current reports, analytics and planning applications. The quantity of all users in 'user support' is identified by the authorization component (user directory) of the BI\&A system used.

Since development, consulting and training allow costs to be allocated in a fair way, the transfer prices 
are calculated on an hourly basis. Here, the monthly total capacity of personnel resources available within the BI\&A department has to be considered. Figure 4 shows an example for calculating the costs for development and the operating cost for a report.

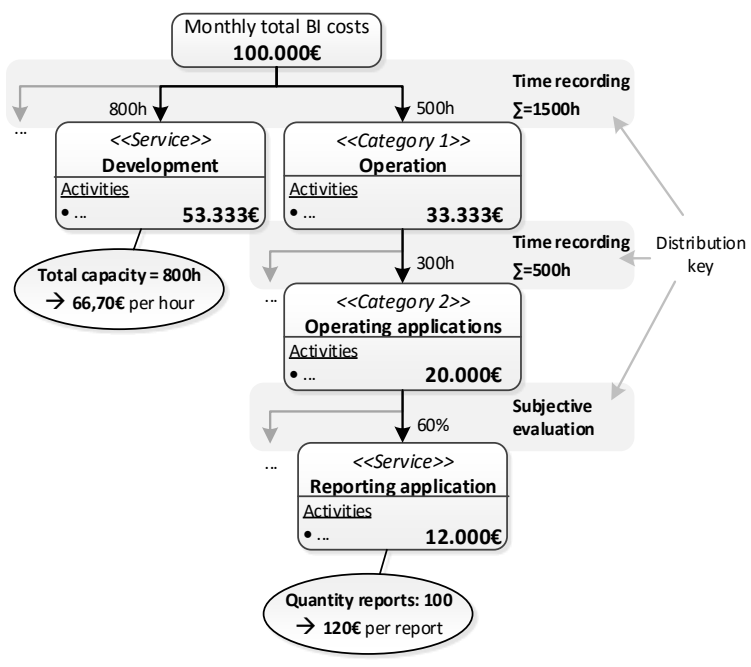

Figure 4. Transfer prices for a report

\subsection{BI\&A service catalog}

The BI\&A service catalog is a summary of all the services, clearly presented for service consumers. The essential foundations for building a service catalog are the cost model and service integration. This catalog could be interpreted within the company as a marketing tool, which also communicates the value of the BI\&A department to consumers [9]. Figure 5 shows an example of how the service BI\&A 'reporting application' may be described.

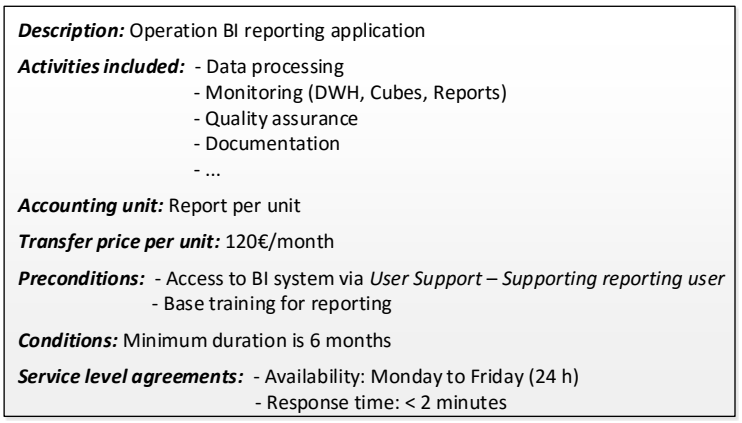

Figure 5. Service for reporting application

In addition, it is conceivable that service level agreements (SLA) [19] can be specified. Through the service catalog, service consumers are informed about the transfer prices of single BI\&A services and the composition of BI\&A activities [3]. With costs per service, a BI\&A application is calculable when considering all services used in the development as well as in the operations stage. This paper excludes a comprehensive definition of the service catalog. A detailed approach is presented by Krcmar [17].

\section{Conclusion and outlook}

The main challenge in this paper was to propose a process model that rendered the BI\&A cost pool accountable and improved cost transparency. This is especially difficult in a heterogeneous system landscape with technical as well as functional complexity which for the most part is multi layered. Seeing it from a BI\&A perspective, price determination for BI\&A applications currently operational and planned BI\&A projects is difficult. The BIASOCA offers a practicable approach to 1 . determine the total BI\&A costs; 2. make these costs calculable by applying a defined, company-specific allocation structure in a cost model; 3 . render services understandable to consumers with transfer prices communicated by a BI\&A service catalogue. By differentiating between fixed and variable cost activities, cost allocation becomes more appropriate.

A fair allocation of BI\&A activities is enabled by the subsequent construction of the cost model. It is, however, impossible to accomplish this requirement in full. One reason is that, in practice, it quickly becomes uneconomical for the BIASOCA to charge every information need requested. Furthermore, implementing this approach causes additional costs, e.g. for time recording. These costs have to be considered and therefore the BIASOCA has to be implemented on a company-specific basis (in an iterative way by increasing accuracy). Beyond that, an allocation based on measuring the load of single BI\&A system components is too complex and expensive. Therefore, to approximate a fair allocation and equal treatment of all service consumers, the operating costs for the BI\&A application types defined in the cost model are charged with a fee through a BI\&A service. This pragmatism leads to a transparent and comprehensible understanding from the service consumer point of view and makes its implementation economically justifiable. Through the process model presented, we are able to:

- increase cost transparency,

- allocate BI\&A costs to the consumers,

- $\quad$ sensitize service consumers to the importance of using BI\&A resources economically,

- cost BI\&A applications or projects prior to development (e.g. for make-or-buy purposes),

- $\quad$ support BI\&A resource planning issues through service consumer demands, 
- value BI\&A requirements in comparison to the perceived benefit, i.e. BI\&A requirements can be put into a meaningful order of business priority,

- assume that the quality of requirements definition will increase and that shorter development cycles will therefore be possible,

- support regular benchmarking and, if required, deletion of BI\&A applications.

The future aim is to evaluate the BIASOCA in expert interviews and implement the design concept to analyze its function in practice. With implementation, user behavior will have to be analyzed for changes. Another point we want to examine is how this approach might be adapted for decentralized BI\&A environments. The evolutional nature makes it possible to refine the cost model with future services to allow a more precise form of accounting. Further analysis is needed of how accurate costing needs to be as a function of company size or BI\&A degree of maturity. We expect the introduction of our concept to result in an improvement in the overall situation of in-house BI\&A departments.

\section{References}

[1] Baars, H. and H.-G. Kemper, "Business intelligence in the cloud?", PACIS 2010 Proceedings, 2010.

[2] Berghout, E. and D. Remenyi, "The Eleven Years of the European Conference on IT Evaluation: Retrospectives and Perspectives for Possible Future Research", Electronic Journal of Information Systems Evaluation, 8(2), 2005, pp. 81-98.

[3] Bertleff, C., "Einführung einer ITLeistungsverrechnung zur Unterstützung des strategischen IT-Controllings.", HMD - Praxis der Wirtschaftsinformatik(217), 2001, pp. 57-66.

[4] Brandl, R., M. Bichler, and M. Strobel, "Cost accounting for shared IT infrastructures", Wirtschaftsinformatik, 49(2), 2007, pp. 83-94.

[5] Cannon, D., D. Wheeldon, S. Lacy, and A. Hanna, ITIL service strategy, 2nd edn., TSO, London, 2011.

[6] Chen, H., R.H.L. Chiang, and V.C. Storey, "Business Intelligence and Analytics: From Big Data to Big Impact", MIS quarterly, 36(4), 2012, pp. 1165-1188.

[7] Friedl, G., C. Hofmann, and B. Pedell, Kostenrechnung, 1st edn., Vahlen, Franz, München, 2010.

[8] Frisch, J., "Effizientes Finanzreporting erhöht das Vertrauen und senkt Kosten", isreport(7+8/2012), 2012, pp. 10-12.

[9] Gansor, T., A. Totok, and S. Stock, Von der Strategie zum Business Intelligence Competency Center (BICC): Konzeption - Betrieb - Praxis, Hanser, München, 2010.

[10] Gibson, M., D. Arnott, and I. Jagielska, "Evaluating the Intangible Benefits of Business Intelligence: Review \& Research Agenda", Decision Support in an Uncertain and
Complex World: The IFIP TC8/WG8.3 International Conference 2004, 2004, pp. 295-305.

[11] Hagerty, J., R.L. Sallam, and J. Richardson, "Magic quadrant for business intelligence platforms", 2012 (http://www.gartner.com/id=1915014, 11-10-2015)

[12] Hamel, F., T.P. Herz, F. Uebernickel, and W. Brenner, "State of the art: Managing costs and performance of Information Technology", AMCIS 2010 Proceedings(Paper 516), 2010.

[13] Horakh, T.A., H. Baars, and H.-G. Kemper, "Mastering Business Intelligence Complexity-A ServiceBased Approach as a Prerequisite for BI Governance", AMCIS 2008 Proceedings, 2008, p. 333.

[14] Kargl, H. and M. Kütz, IV-Controlling, 5th edn., Oldenbourg, München u. a., 2007.

[15] Kemper, H.-G., H. Baars, and T.A. Horakh, "Business Intelligence Outsourcing - A Framework", in Proceedings of the Fifteenth European Conference on Information Systems, ECIS 2007, St. Gallen, Switzerland, 2007, H. Österle, J. Schelp, and R. Winter, Editors. 2007. University of St. Gallen.

[16] Klesse, M., "Methode zur Gestaltung einer Leistungsverrechnung für DWH Competence Center", in Active Enterprise Intelligence ${ }^{\mathrm{TM}}$, J. Töpfer and R. Winter, Editors. 2008. Springer Berlin Heidelberg.

[17] Krcmar, H., Informationsmanagement, 5th edn., Springer, Berlin, 2010.

[18] Lönnqvist, A. and V. Pirttimäki, "The Measurement of Business Intelligence", Information Systems Management, 23(1), 2006, pp. 32-40.

[19] Ludwig, H., A. Keller, A. Dan, R. King, and R. Franck, "A Service Level Agreement Language for Dynamic Electronic Services", Electronic Commerce Research, 3(1), 2003, pp. 43-59.

[20] Miller, G.J., D. Bräutigam, and S.V. Gerlach, Business intelligence competency centers: A team approach to maximizing competitive advantage, John Wiley \& Sons, Hoboken, N.J, 2006.

[21] Moss, L.T. and S. Atre, Business intelligence roadmap: The complete project lifecycle for decisionsupport applications, Addison-Wesley, Boston, MA, 2003.

[22] Negash, S., "Business intelligence", The Communications of the Association for Information Systems, 13(1), 2004, p. 54.

[23] Peco, M., TDWI world conference Las Vegas 2014: TDWI Project Management for Business Intelligence, The Data Warehousing Institute, Renton, 2014.

[24] Popovic, A., T. Turk, and J. Jaklic, "Conceptual Model of Business Value of Business Intelligence Systems", Management, 15(1), 2010, pp. 5-30.

[25] Tullis, T. and B. Albert, Measuring the user experience: Collecting, analyzing, and presenting usability metrics, Elsevier/Morgan Kaufmann, Amsterdam, 2008.

[26] van Maanen, H. and E. Berghout, "Cost management of IT beyond cost of ownership models: a state of the art overview of the Dutch financial services industry", Evaluation and Program Planning, 25(2), 2002, pp. 167173.

[27] Wu, J., "Calculating the ROI for Business Intelligence Projects", $2000 \quad$ (http://www.informationmanagement.com/news/2487-1.html, 11-10-2015) 